\title{
Mortality risk versus food quality trade-offs in ants: patch use over time
}

\author{
PETER NONACS and LAWRENCE M. DILL Behavioural Ecology \\ Research Group, Department of Biological Sciences, Simon Fraser University, Burnaby, Canada
}

\begin{abstract}
Foragers of the ant species Lasius pallitarsis (Provancher) and Myrmica incompleta Provancher were given access to two food patches that differed in nutritive quality. In about half of the trials, the higher quality patch also had a mortality risk for the foragers in the form of a large Formica subnuda Emery ant located along the trail. Colonies were given access to the food for 4 or $24 \mathrm{~h}$, every second day.

2. Use of the higher quality patch by L.pallitarsis foragers was depressed by the mortality risk. In contrast to the predictions of a food stress hypothesis, foragers used the risky patch more in the longer access trials. This appears due to a decline in the activity level of the F.subnuda, which results in a significantly lower mortality risk per trip.

3. M.incompleta also significantly decreased their use of the higher quality patch when a F.subnuda was present. However, the length of time a colony had access to the patches had no effect on the use of the risky patch. M.incompleta foraging behaviour seems relatively insensitive to short-term food stress or changing levels of mortality risk.

4. The differences between species in their exploitation of patches and reactions to F.subnuda are discussed in terms of the species' natural history.
\end{abstract}

Key words. Ants, foraging behaviour, Lasius pallitarsis, Myrmica incompleta, patch use, predation risk, trade-offs.

\section{Introduction}

A successful ant forager must not only find a food item, but survive to return it to the colony, and the most successful colonies should have foragers capable of maximizing energy intake and minimizing predation losses. Consistent with energy maximizing, several species have been shown to value nearby patches more than

Correspondence: Dr Peter Nonacs, Museum of Comparative Zoology, Harvard University, Cambridge, MA 02138, U.S.A. distant ones, to rank food items by their profitabilities, to increase selectivity further from the colony, and to be sensitive to time delays in collecting food (Taylor, 1977; Davidson, 1978; Fowler, 1987; Holder Bailey \& Polis, 1987).

There is also considerable evidence that ant colonies change their foraging patterns in response to worker loss or to avoid aggressive competitors (Traniello, 1989). Simulated predation of workers from the area surrounding nest entrances can result in the cessation of foraging activity by Pogonomyrmex and Myrmecocystus species (Gentry, 1974; Whitford \& Bryant, 1979; Shaffer \& Whitford, 1981; 
Munger, 1984; Gordon, 1986). Predation at nest entrances may even lead to total cessation of above ground activity. However, when only certain patches in the foraging area are dangerous, Lasius pallitarsis (Provancher) foragers concentrate their activities in safe patches (Nonacs \& Dill, 1988). Furthermore, when colonies are given access to two patches, in a situation where the patch with the higher food quality has an associated mortality risk, the ants make behavioural trade-offs. These trade-offs appear to be based on the consequences for colony growth. Foragers value risky and safe patches equally when the extra colony growth to be gained from the risky patch approximately offsets the forager mortality rate (Nonacs \& Dill, 1990). Finally, successful L.pallitarsis foragers appear to be able to communicate the presence of danger along the trail. Nestmates can then use information about both risk and food quality in determining whether to exploit a food patch (Nonacs, 1990).

The cost to an ant colony of lost food is likely to be greatest when energy stores are low and it may then increase foraging effort (Cosens \& Toussaint, 1985; Holder Bailey \& Polis, 1987). Colonies with reduced access to food are likely to be more energy stressed and more willing to take mortality risks. In this study, we examine how the duration of access to food patches by colonies of L.pallitarsis and Myrmica incompleta Provancher affects their reactions to the mortality risk associated with foraging. Varying the length of time colonies have access to food should vary colony energy reserves; it is predicted that colonies with shorter access time will value food intake more and be more willing to take risks than will colonies with longer access times.

\section{Methods}

In the laboratory, twelve L.pallitarsis and eight $M$ incompleta colonies were given access to two equidistant patches in an apparatus and under conditions detailed in Nonacs \& Dill (1988). The patches contained a liquid ant diet of sucrose, casein, salts, minerals and vitamins dissolved in distilled water (Nonacs, 1988). We used five diet levels of either full strength, or diluted to $1 / 2,1 / 4,1 / 8$ or $1 / 16$ concentration. In a trial, each patch contained a different diet concentration so that the nutritive values of the two patches were never equal. With the five diets this resulted in ten patch pairings, with either 2-, 4-, 8- or 16-fold differences in relative concentration.

Trials began by collecting foraging individuals near the nest and placing equal numbers (two to five individuals) in the two food patches. Food was available from a coil of Tygon tubing (1.5 $\mathrm{mm}$ interior diameter) with both ends blocked with cotton wool so that there was a constant droplet of food which replenished itself as the ants fed. After the foragers became satiated, the patches were connected via Tygon tubing ( $3.5 \mathrm{~mm}$ interior diameter) to the home area; the ants returned (a distance of $50 \mathrm{~cm}$ ) from both food patches in roughly the same numbers and at the same time. Any trial in which there was not an approximately symmetrical return of foragers was discarded.

The initial foragers never encountered danger or risk. Risk, in the form of a Formica subnuda Emery worker, was added to the side with the higher diet concentration (henceforth referred to as 'risky') in roughly half the trials. This larger ant was restricted to one $5 \mathrm{~cm}$ area along the trail to and from the patch by constructing a tube-within-a-tube pathway. The inner tube was of Tygon with openings large enough to allow free passage of L.pallitarsis or M.incompleta foragers, but too small for the F.subnuda to escape from the larger, outer tube. Therefore, foragers could physically contact and, potentially, be killed by the larger ant within this 'arena'. In trials designated as risky, we placed a large $F$.subnuda worker into the arena after the initial foragers had passed on their inward trip to the colony, but before they or new recruits could return. The experiment tested whether the foragers chose between the two patches based only on nutritive difference or also took safety into account.

The twenty colonies were equally split between the two trial durations ( 4 or $24 \mathrm{~h}$ ) and individual colonies experienced only one duration. All colonies experienced at least one trial with risk and one trial without risk for each of the four possible relative differences in patch concentration (but not all of the ten possible pairings of absolute patch value). One trial was run every second day, resulting in colonies having access to food for either 4 or $24 \mathrm{~h}$ out of 48. We assumed that colonies with only $4 \mathrm{~h}$ 
access would be more food-stressed than those with $24 \mathrm{~h}$ access. The presentation order and patch position of concentration pairings and risk were randomized across all trials for each colony.

At the end of each trial, the condition of the F.subnuda and the number of dead foragers in the arena were recorded. The food tubes were weighed before and after a trial. The change in weight due to evaporation was estimated and corrected for by measuring weight loss in food tubes kept concurrently in a similar apparatus, but without ants. Patclı preference was measured as the proportion of all food taken which came from the higher concentration patch, and the number of food loads returned to the colony was calculated using an estimated load size of $0.3 \mathrm{mg}$ (Nonacs, 1988). Results were discarded for trials in which the amount taken was very small and could have been unduly influenced by errors in measuring evaporative loss (less than $5.0 \mathrm{mg}$ in $4 \mathrm{~h}$ or $10.0 \mathrm{mg}$ in $24 \mathrm{~h}$ trials).

All colonies had larvae and 75-250 workers, but only four colonies of L.pallitarsis and six colonies of M.incompleta had queens. These were split evenly between trial duration groups. In previous foraging experiments, queen presence did not influence patch preference or response to risk (Nonacs, 1988; Nonacs \& Dill, 1988).

Although colonies were assigned in a manner to minimize differences in terms of queen and worker numbers between trial duration groups, there could still have been unmeasured intrinsic differences between colonies in their willingness to take risks. To control for this possibility, in a second experiment we repeated a subset of the $24 \mathrm{~h}$ trials, but measured the amount of food taken from the patches after both 4 and $24 \mathrm{~h}$. We used nine L.pallitarsis colonies (all with larvae, three with queens from the previous experiment and six newly-collected queenless colonies) and gave them choices between a patch that always had full strength food with associated risk, and a safe patch with food quality varying from $1 / 2$ to $1 / 16$ strength. All nine colonies experienced every relative patch combination.

\section{Results}

Means of the proportional use of the higher concentration patches were calculated for each colony at the four levels of relative concentration differences. These means were analysed by a repeated measures ANOVA (data arcsine square root transformed) with risk presence, food concentration difference between patches ('diet') and trial duration as factors. Risk and diet had large main effects in both species $\left(F_{1.10}=208.0\right.$ for risk and $F_{3,30}=19.7$ for diet in L.pallitarsis; $F_{1,6}=16.4$ for risk and $F_{3,18}=6.5$ for diet in M.incompleta; $P<0.007$ in each case). When risk was present, there was a dramatic decline in the preference for the higher concentration (but risky) patch at both trial durations for L.pallitarsis (Fig. 1) and in $4 \mathrm{~h}$ trials for M.incompleta (Fig. 2; the overall effect is less in $24 \mathrm{~h}$ trials because colonies showed less preference for the higher concentration patch in trials without risk). Decreased relative food concentration of the poorer patch generally

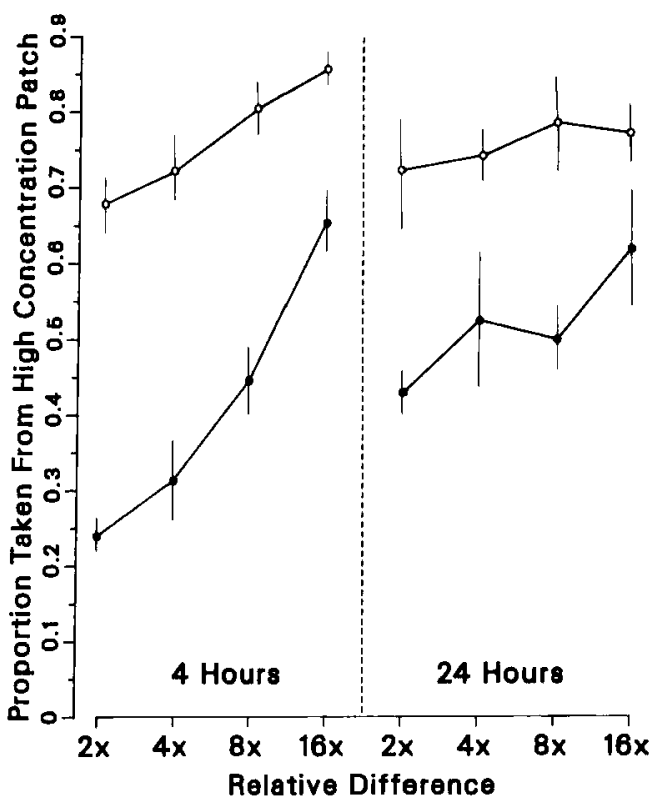

Fig. 1. Patch use by twelve L.pallitarsis colonies in response to mortality risk, food quality differences and trial duration. The proportion of all food taken which came from the higher concentration patch ( $\pm \mathrm{SE}$ ) is plotted for the four relative differences in patch concentration. Trials either had no mortality risk associated with either patch $(0)$ or risk associated with the higher concentration patch $(\bullet)$. 


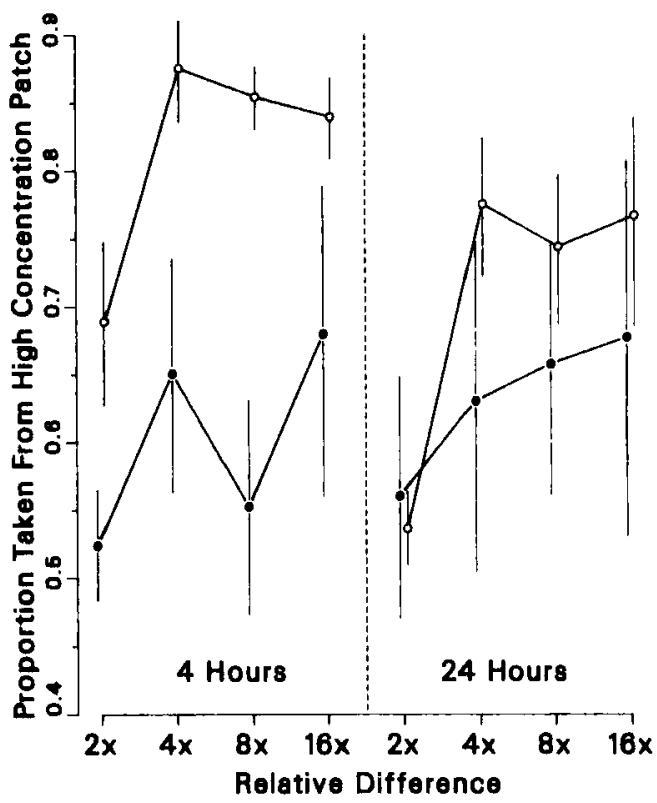

Fig. 2. Patch use by eight $M$.incompleta colonies in response to mortality risk, food quality differences and trial duration. The proportion of all food taken which came from the higher concentration patch. $( \pm \mathrm{SE}$ ) is plotted for the four relative differences in patch concentration. Trials either had no mortality risk associated with either patch $(O)$ or risk associated with the higher concentration patch $(\bullet)$.

resulted in increased preference for the higher quality patch in both species. In neither species was there a significant interaction effect between risk and diet.

In M.incompleta there were no significant interactions between any of the factors but in L.pallitarsis there was a significant interaction between diet and trial duration $\left(F_{3,30}=4.6 ; P=\right.$ $0.009)$. At relatively small concentration differentials, colonies in $24 \mathrm{~h}$ trials took more from the higher quality food patch than did colonies in $4 \mathrm{~h}$ trials; the reverse was true at large differentials. The biological implications of this result are unclear.

Risk and trial duration also interacted significantly in L.pallitarsis $\left(F_{1,10}=8.7 ; P=0.015\right)$. Colonies appeared less sensitive to risk in longer trials, a result not predicted by the food stress hypothesis. However, the stress hypothesis assumes a constant level of risk, which may not have been true. In some cases, the F.subnuda died during a trial. As more F.subnuda died in the $24 \mathrm{~h}$ trials, this would have made these trials less risky. When trials where the large ant was found dead were removed from the data set, however, the effect of trial duration was still present. Nevertheless, in longer trials the activity level of the $F$.subnuda may have declined.

To test this, we compared the number of ants killed per food load brought back from the risky patch in the two trial durations (Table 1). The chances of getting killed were significantly less per load returned to the colony in $24 \mathrm{~h}$ trials than in $4 \mathrm{~h}$ trials, for both forager species.

Usually foragers appeared to avoid the F.subnuda as much as possible and rarely more than a few were killed per trial. Six or fewer foragers died in ninety-eight of the 124 trials in which any foragers died. However, occasionally both species would attack the F.subnuda in large numbers, sharply increasing the number of workers killed. These trials were probably more reflective of a colony defence reaction than of the dangers of a single foraging trip to an individual. Therefore, the calculation of foraging mortality rates does not include trials in which ten or more foragers were found dead. This point was chosen as the cutoff because for both species it included the first zero category in the data set (i.e. there were no trials in which nine L.pallitarsis or ten M.incompleta foragers were killed). By this criterion M.incompleta

Table 1. The number of foragers killed and food loads returned to colonies. Trials were 4 or $24 \mathrm{~h}$ long. Mortality rate, calculated as the number of toragers killed per load returned, was significantly lower in $24 \mathrm{~h}$ trials (for L.pallitarsis, $\chi^{2}=3.626, P<0.05$, one tailed; for $M$.incompleta, $\chi^{2}=58.800, P<0.001$, onc tailed).

\begin{tabular}{|c|c|c|c|}
\hline Trial & $\begin{array}{l}\text { No. } \\
\text { killed }\end{array}$ & $\begin{array}{l}\text { No. of } \\
\text { loads returned }\end{array}$ & Mortality rate \\
\hline \multicolumn{4}{|c|}{ Lasius pallitarsis } \\
\hline $4 \mathrm{~h}$ & 54 & 2487 & 0.0217 \\
\hline $24 \mathrm{~h}$ & 92 & 5883 & 0.0156 \\
\hline Total & 146 & 8370 & 0.0174 \\
\hline \multicolumn{4}{|c|}{ Myrmica incompleta } \\
\hline $4 h$ & 82 & 2140 & 0.0383 \\
\hline $24 \mathrm{~h}$ & 80 & 6648 & 0.0120 \\
\hline Total & 162 & 8788 & 0.0184 \\
\hline
\end{tabular}




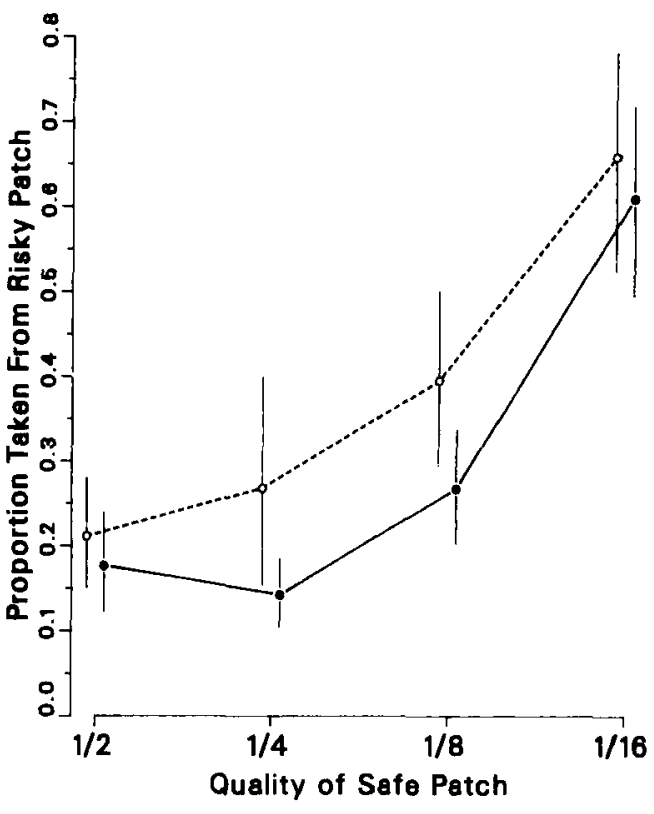

Fig. 3. Patch use by nine L.pallitarsis colonies over $24 \mathrm{~h}$. The proportion of all food taken $( \pm S E)$ which came from the risky patch is shown for the first $4 \mathrm{~h}(\bullet)$ and last $20 \mathrm{~h}(0)$. The food in the risky patch was always full strength. The quality of the food in the safe patch ranged from $1 / 2$ to $1 / 16$ the concentration in the risky patch.

colonies responded aggressively toward the F.subnuda more often than did L.pallitarsis (in sixteen of ninety-three trials, eleven to thirty M.incompleta foragers were killed; cf. four of 161 trials with ten to fourteen foragers killed for L.pallitarsis).
The results of the second experiment, which examined the amount of food taken from the patches over time, also suggested that foragers were responding more to changes in risk than to possible food shortfalls. L.pallitarsis colonies significantly increased their proportionate use of the risky patch over the duration of a trial (matched pair $t$-test, $t=1.83, \mathrm{df}=35, P=0.038$, one-tailed, Fig. 3). Unfortunately, mortality risk per load could not be measured by counting dead ants at $4 \mathrm{~h}$ without disturbing both the F.subnuda and the L.pallitarsis foragers. Therefore, it is not possible to determine whether risk significantly decreased with time. In the last $20 \mathrm{~h}$, the hourly feeding rate was substantially reduced (Table 2 ). These reduced feeding rates suggest colony satiation, and colonies with ample energy reserves should (if anything) be more likely to avoid mortality risk. Therefore, the change in patch use was not consistent with changes predicted by a food stress hypothesis and, like the results of the previous experiment, suggests that foraging $L$.pallitarsis are sensitive to short-term variation in risk of predation.

\section{Discussion}

There were two notable differences between the foraging behaviour of the two species. First, L.pallitarsis responded differently to mortality risk across the two trial durations whereas M.incompleta did not. This result is due, in part, to M.incompleta showing less avoidance

Table 2. Patch use by nine L.pallitarsis colonies over $24 \mathrm{~h}$. The average amount of food $(\mathrm{mg}) \pm \mathrm{SE}$, taken in a trial from both patches in total and per hour, is given at 4 and $24 \mathrm{~h}$. The risky patch always contained full strength diet.

\begin{tabular}{|c|c|c|c|c|}
\hline \multirow{3}{*}{$\begin{array}{l}\text { Diet in } \\
\text { safe patch }\end{array}$} & \multicolumn{4}{|c|}{ Weight eaten (mg) } \\
\hline & \multicolumn{2}{|l|}{ Total } & \multicolumn{2}{|l|}{ Per hour } \\
\hline & First $4 \mathrm{~h}$ & Last $20 \mathrm{~h}$ & First $4 \mathrm{~h}$ & Last $20 \mathrm{~h}$ \\
\hline $1 / 2$ & $57.24 \pm 12.70$ & $46.99 \pm 11.97$ & $14.31 \pm 3.17$ & $2.35 \pm 0.60$ \\
\hline $1 / 4$ & $45.64 \pm 9.24$ & $58.76 \pm 10.93$ & $11.41 \pm 2.31$ & $2.94 \pm 0.55$ \\
\hline $1 / 8$ & $26.97 \pm 5.39$ & $49.56 \pm 11.85$ & $6.74 \pm 1.35$ & $2.48 \pm 0.59$ \\
\hline $1 / 16$ & $35.44 \pm 10.18$ & $52.43 \pm 16.18$ & $8.86 \pm 2.55$ & $2.62 \pm 0.81$ \\
\hline Average & $41.32 \pm 5.03$ & $51.94 \pm 6.21$ & $10.33 \pm 1.26$ & $2.60 \pm 0.31$ \\
\hline
\end{tabular}


of the risky patch under all conditions, thus limiting the magnitude of any risk/trial duration interaction (compare Fig. 1 to Fig. 2). In conjunction with foraging proportionally more in the risky patches, M.incompleta colonies were also much more likely than L.pallitarsis to respond aggressively to the F.subnuda.

Second, the species differed in patch choice under conditions where risk was absent. As the relative difference in patch concentrations increased, L.pallitarsis generally took proportionally more food from the higher concentration patch (Fig. 1), and even with the smallest relative differences, colonies showed a marked preference for the higher concentration patch. In contrast, $M$.incompleta showed no increased preference for the higher concentration patch as the relative differences increased from 4 - to 16-fold (Fig. 2), and exhibited much less discrimination between patches with only 2 -fold differences (in fact, in $24 \mathrm{~h}$ trials, the patch use is not significantly different from random). The different responses across concentration pairings may indicate that the two species are not equal in their sensory capabilities.

Another possibility is that the two species evaluate patch quality using different criteria. The analysis presented here considers all patches of equal relative concentration differences to be equal in effect. Ants could, however, react to absolute difference in nutrient concentrations or to the growth consequences each diet level has for the colony. The former is not a significant predictor of patch choice (Nonacs, 1988), but in L.pallitarsis the willingness of foragers to use risky patches is correlated closely with gain in terms of colony growth (Nonacs \& Dill, 1990). The growth consequences of the different patches are unknown for $M$.incompleta and may not be the same as for L.pallitarsis.

The results of this study also suggest that L.pallitarsis foragers' ranking of patches, unlike that of M.incompleta, is sensitive to changes in the level of associated risk. The L.pallitarsis colonies used the rich, risky patches significantly more in the $24 \mathrm{~h}$ trials than in the $4 \mathrm{~h}$ trials, probably because of a lowered probability of dying per successful foraging trip in the longer trials. Patch use by individual colonies at both 4 and $24 \mathrm{~h}$ confirmed the results of the first experiment: the proportional use of the risky, foodrich patch increased in the last $20 \mathrm{~h}$ of a trial. Decline in actual or perceived risk levels appears to be the only logical explanation for this change in behaviour.

Once on the trail to a food patch, L.pallitarsis workers change their behaviour only if they physically encounter a $F$.subnuda. Dead nestmates and the odour of an aroused F. subnuda worker do not, by themselves, affect patch choice (Nonacs \& Dill, 1988). Upon encountering a F.subnuda worker, L.pallitarsis foragers usually retreat. This depresses patch use because the surviving worker reduces her foraging activity towards that patch. Also, surviving foragers will communicate the presence of risk to their nestmates: if only one food patch is available, the appearance of F.subnuda along the trail will halt all further recruitment if the food is of low quality (Nonacs, 1990). With two patches, as in these experiments, activity is shifted away from the riskier patch.

The a priori prediction that colonies in 4 h trials would be less sensitive to mortality risk was not upheld. Mincompleta colonies were affected neither by food stress nor lowered risk. L.pallitarsis colonies in $4 \mathrm{~h}$ trials used the risky patches less than in $24 \mathrm{~h}$ trials, suggesting that foragers were not as affected by lower colony food reserves as they were by the level of risk. If risk could have been kept constant and equal across all trial durations, foragers in the $24 \mathrm{~h}$ trials may have shown the greater risk avoidance.

The risk posed by F.subnuda workers may not be equivalent for the two species. L.pallitarsis forms huge colonies (over 100,000 individuals) and nests in dead, but solid, wood. Their numerical size and the small passages in the interiors of colonies would appear to make mature colonies safe from being severely raided by F.subnuda. Therefore, although L.pallitarsis foragers might occasionally be at risk, the colony itself may not be threatened. However, mature M.incompleta colonies are not nearly so large (no more than several thousand ants, and often many less) and nest primarily in loose soil, under rocks or debris, where they seem more vulnerable to F.subnuda raids. Therefore, a F.subnuda worker may signal an imminent danger to both M.incompleta foragers and their colony. This may explain their more frequent attacks on the F.subnuda in the experimental apparatus.

The importance of nest architecture has perhaps been inadequately stressed in explaining 
distribution of competing species. It is clear that F.subnuda would be dominant over either L.pallitarsis or M.incompleta at food sources because of their size and fighting ability. Such foraging dominance hierarchies may explain many, but not all aspects of species distributions (Brian et al., 1966; Savolainen \& Vepsäläinen, 1988). If a species like L.pallitarsis inhabits a secure nest site, it may be able to use superior food location and recruitment skills to coexist with or perhaps even outcompete a much larger, stronger species. However, species like $M$.incompleta, even if they have vastly superior foraging skills, may not be able to exist in close proximity with species capable of raiding their vulnerable nest sites.

Ant colonies must integrate many diverse activities in the course of a day to be successful and, furthermore, the performance of these activities must be affected by the community of competitors and predators surrounding the colony. However, researchers have often concentrated on only one aspect, such as food collection (Taylor, 1977; Davidson, 1978; Fowler, 1987; Holder Bailey \& Polis, 1987) or the response to above-ground predation risk (Gentry, 1974; Whitford \& Bryant, 1979; Shaffer \& Whitford, 1981; MacKay, 1982; Munger, 1984). These studies have added greatly to our understanding of ant ecology, but, as pointed out by Gordon (1989), group properties of colonies may be obscured or even erroneously predicted when behaviours or tasks are considered in isolation. Future research may now be best served by considering how the often conflicting demands of foraging, avoiding predation, raising brood, and maintaining and defending nest integrity are balanced. Fundamental understanding of the behaviour of ant colonies requires examining not only how a particular goal is accomplished, but also the group-level dynamics of how multiple goals are achieved simultaneously, and the behavioural trade-offs this requires, in the context of a species' natural history.

\section{Acknowledgments}

We thank Mark Abrahams, Ralph Cartar, Mart Gross, Alton Harestad, Guy Martel, Bernie Roitberg, Paul Schmid-Hempel, James Traniello, Mark Winston, Ron Ydenberg and two referees for comments and criticisms.
Alex Fraser, Dave Inglis, Rae Suttie and John Wieczorek helped with collecting and maintaining the ants. André Francoeur (University of Quebec/Chicoutimi) confirmed all species identification and has the type specimens in his collection. The study was supported in part by NSERC Canada grant A6869 to L.M.D. and Simon Fraser University Graduate Fellowships to P.N.

\section{References}

Brian, M.V., Hibble, J. \& Kelly, A.F. (1966) The dispersion of ant species in a southern English heath. Journal of Animal Ecology, 35, 281-290.

Cosens, D. \& Toussaint, N. (1985) An experimental study of the foraging strategy of the wood ant Formica aquilonia. Animal Behaviour, 33, $541-552$.

Davidson, D. (1978) Experimental tests of the optimal diet in two social insects. Behavioral Ecology and Sociobiology, 4, 35-41.

Fowler, H.G. (1987) Communication and optimal foraging in the ant, Tetramorium caespitum ( $\mathrm{Hy}$ menoptera: Formicidae). Ciencia e Cultura, 39 , 301-303.

Gentry, J.B. (1974) Response to predation by colonics of the Florida harvester ant, Pogonomyrmex badius. Ecology, 55, 1328-1338.

Gordon, D.M. (1986) The dynamies of the daily round of the harvester ant colony (Pogonomyrmex barbatus). Animal Behaviour, 34, 1402-1419.

Gordon, D.M. (1989) Caste and change in social insects. Oxford Surveys in Evolutionary Biology, 6 , $55-72$.

Holder Bailey, K. \& Polis, G.A. (1987) Optimal and central-place foraging theory applicd to a desert harvester ant, Pogonomyrmex californicus. Oecologia, 72, 440-448.

Mackay, W.P. (1982) The effect of predation of western widow spiders (Araneae: Theridiidae) on harvester ants (Hymenoptera: Formicidac). Oecologia, 53, 406-411.

Munger, J.C. (1984) Long-term yield from harvester ant colonies: implications for horned lizard foraging. Ecology, 65, 1077-1086.

Nonacs, P. (1988) Foraging, mortality risk and colony growth in ants. Ph.D. thesis, Simon Fraser University, Burnaby, B.C.

Nonacs, P. (1990) Death in the distance: mortality risk as information for foraging ants. Behaviour, $112,23-35$.

Nonacs, P. \& Dill, L.M. (1988) Foraging response of the ant Lasius pallitarsis to food sources with associated mortality risk. Insectes Sociaux, 35, $293-303$. 
Nonacs, P. \& Dill, L.M. (1990) Mortality risk versus food quality trade-offs in a common currency: ant patch preferences. Ecology (in press).

Savolainen, R. \& Vepsäläinen, K. (1988) A competition hicrarchy among boreal ants: impact on resource partitioning and community structure. Oikos, 51, 135-155.

Shaffer, D.T. \& Whitford, W.G. (1981) Behavioral responses of a predator, the round-tailed horned lizard, Phrynosoma modestum and its prey, honey pot ants Myrmecocystus spp. American Midland Naturalist, 105, 209-216.

Taylor, F. (1977) Foraging behavior of ants: exper- iments with two species of Myrmecine ants. Behayioral Ecology and Sociobiology, 2, 147-167.

Traniello, J.F.A. (1989) Chemical trail systems, orientation, and territorial interactions in the ant Lasius neoniger. Journal of Insect Behavior, 2, 339-354.

Whitford, W.G. \& Bryant, M. (1979) Behavior of a predator and its prey: the horned lizard (Phrynosoma cornutum) and harvester ants (Pogonomyrmex spp.). Ecology, 60, 686-694.

Accepted 9 March 1990 